\title{
Monoclonal antibodies show Listeria monocytogenes in necropsy tissue samples
}

\author{
J MCLAUCHLIN, * A BLACK, $\dagger$ H T GREEN, J Q NASH, $†$ A G TAYLOR* \\ From *the Division of Microbiological Reagents and Quality Control, Central Public Health Laboratory, \\ Colindale, London, †Public Health Laboratory, The William Harvey Hospital, Ashford, Kent, and the $\ddagger$ Walton \\ Hospital, Liverpool
}

SUMMARY Stable mouse monoclonal hybridoma cell lines secreting antibodies against Listeria monocytogenes were produced. Antibodies from two of these cell lines (designated CL2 and CL17) have been partially characterised. The specificities of these antibodies were assessed using indirect immunofluorescence antibody tests and L monocytogenes (166 strains) grown in vitro, other species of Listeria (21 strains), and bacteria from 14 other genera ( 87 strains). The antibodies were found to be specific for Listeria, and when used in combination, reacted with almost all strains of $L$ monocytogenes. A simple and rapid direct immunofluorescence technique was developed, and the presence of $L$ monocytogenes was shown in necropsy tissue from three patients where listeriosis had been confirmed by isolation of the bacterium. Bacteria were also confirmed using one of these antibodies in necropsy tissue from one further patient in whom listeriosis was suspected, but not confirmed by the cultivation of $L$ monocytogenes.

Listeria monocytogenes is a Gram positive bacillus, which was first described in England as causing infection in laboratory animals. ${ }^{\prime}$ The disease caused by this bacterium (listeriosis) is now known to affect a wide range of animals including man, ${ }^{2}$ in whom listeriosis has become increasingly recognised as an important cause of sepsis during the perinatal period, and also of opportunistic infections (particularly of the central nervous system) in adults and juveniles. ${ }^{3}$

Over the past decade there has been an apparent increase in the incidence of listeriosis in Britain in both man, ${ }^{45}$ and domestic animals ${ }^{67}$; the reasons for this increase are not known. The epidemiology of human listeriosis has remained obscure, although outbreaks in North America have highlighted the possibility of food borne infection. ${ }^{8-10}$ The growth characteristics and distribution of this bacterium make it an ideal candidate for transmission through food, especially as a contaminant of refrigerated food. It is not known to what extent food borne listeriosis takes place.

Although the genus Listeria was originally considered to contain one species ( $L$ monocytogenes), seven additional species are now also recognised. 112 These are: $L$ innocua, $L$ welshimeri, $L$ seeligeri, $L$ ivanovii, $L$ grayi, $L$ murrayi and $L$ denitrificans. Bacteria of this genus are ubiquitously distributed in

Accepted for publication 7 April 1988 the environment, and commonly found in the gut and genital tract of healthy people. ${ }^{13} L$ monocytogenes is the major pathogen in both animals and man. ${ }^{514}$ In man, however, occasional infections due to $L$ ivanovii and $L$ seeligeri occur. ${ }^{14-16}$

A serotyping scheme has been described by DonkerVoet and Seeliger ${ }^{17}$ based on agglutination reactions of Listeria with highly absorbed rabbit antisera. This system permits the recognition of a number of somatic and flagellar antigens, and hence the subdivision of $L$ monocytogenes into 13 serovars. These are: $1 / 2 \mathrm{a}, 1 / 2 \mathrm{~b}$, 1/2c, 3a, 3b, 3c, 4a, 4ab, 4b, 4c, 4d, 4e, and 7. ${ }^{18}$ Surveys on the continent of Europe by these and other workers showed that a large proportion of strains of $L$ monocytogenes from both human and animal infections belong to one of a small number of serovars. Strains of $L$ monocytogenes isolated from humans in Britain are similar in this respect as, in a survey of over 700 cases, ${ }^{5} 91 \%$ of all isolates comprised only three serovars $(59 \%$ were serovar $4 \mathrm{~b}, 18 \%$ serovar $1 / 2 a$, and $14 \%$ serovar $1 / 2 b)$.

We previously reported the production of 15 cell lines secreting monoclonal antibodies against $L$ monocytogenes serogroup $4 .^{19}$ We describe here a further monoclonal antibody which reacts with $L$ monocytogenes serogroups $1 / 2$ and 3 , and assess the specificity of this and one of the previously reported antibodies. We also showed the presence of $L$ monocytogenes in necropsy tissue using these antibodies. 


\section{Material and methods}

STRAINS OF BACTERIA

Cultures of $L$ monocytogenes isolated from patients were identified using the criteria of Rocourt et $a,^{22}$ as previously described, ${ }^{23}$ and were serotyped as described by Seeliger and Hohne. ${ }^{18}$

Strains of Listeria were obtained from the National Collection of Type Cultures, Colindale (NCTC), The Institut Pasteur, Paris, France (CIP), and the Special Listeria Culture Collection, University of Wurzburg, Federal Republic of Germany (SLCC). Serological reference strains for the 13 serovars of $L$ monocytogenes tested were: serovar 1/2a NCTC 7973, 1/2b NCTC 10887, 1/2c NCTC 5348, 3a NCTC 5105, 3b SLCC 2540, 3c SLCC 2479, 4a NCTC 5214, 4ab NCTC 10528, 4b NCTC 4885, 4c NCTC 4883, 4d NCTC 10888, 4e SLCC 2378 and 7 NCTC 10890. The type strains of each of the remaining seven species of Listeria tested were: $L$ innocua NCTC 11288, $L$ welshimeri CIP 8149, L seeligeri CIP 100100, L ivanovii CIP 78.42, L grayi NCTC 10815, L murrayi NCTC 10912, and $L$ denitrificans NCTC 10816. The following wild type strains were obtained from the SLCC: $L$ monocytogenes serovar 1/2a (10 strains), $L$ monocytogenes serovar $4 \mathrm{~b}$ (10 strains), $L$ innocua serovar 6a (four strains), $L$ innocua serovar $6 \mathrm{~b}$ (five strains), $L$ ivanovii (five strains). In addition, the following wild-type strains from the DMRQC collection of $L$ monocytogenes (which had been isolated in Britain as they caused disease in humans) were tested: 34 strains of serovar $1 / 2 \mathrm{a}$, eight of serovar $1 / 2 \mathrm{~b}$, seven of serovar 1/2c, nine of serogroup 3, 66 of serovar $4 b$, and 19 strains of serogroup 4 but not $4 \mathrm{~b}$. Strains of bacteria from other genera were obtained from various culture collections (table 1).

\section{PRODUCTION OF MONOCLONAL ANTIBODIES}

Balb/c mice were immunised with three wild-type strains of $L$ monocytogenes which had been isolated from patients with listeriosis in Britain. Spleen cells from hyperimmune mice were fused with plasmacytoma cells, as described previously, ${ }^{20}$ and screened for antibody production using fluorescein isothiocyanate (FITC) conjugated goat anti-mouse antibodies (Tago) in an indirect immunofluorescence test. Cell lines were cloned twice by a limiting dilution technique. For the production of antibody, the hybridoma cell lines were reintroduced into the peritoneal cavity of mice to form an ascitic tumour, and antibody rich ascitic fluid was collected.

Seventeen stable cell lines were generated which produced anti-Listeria antibodies. Antibodies from two of these cell lines (designated CL2 and CL17) were selected for this study. The antibody producing hybridomas resulted from fusions between mouse spleen cells and the plasmocytoma cell line JKAg8653 for CL2, and NSO for CL17. The monoclonal antibody secreting hybridoma CL2 was produced from a mouse inoculated with a serogroup 4 strain of $L$ monocytogenes, and CL17 after inoculation with a serogroup 1/2 strain. Both the antibodies are of the IgM isotype, and direct FITC-antibody conjugates have been prepared using previously described methods. ${ }^{21}$ Optimal results were obtained when FITC was coupled to purified antibody in the molar ratios (FITC:antibody) of 1:40 for CL2, and 1:20 for CL17.

\section{CONDITIONS FOR BACTERIOLOGICAL GROWTH}

Strains of Listeria were grown in vitro at $37^{\circ} \mathrm{C}$ on: Tryptose agar plus $1 \%$ (w:v) glucose (Difco Laboratories, Detroit Michigan, USA), 5\% horse blood agar (Nutrient Agar base No 2, Oxoid Limited, Basingstoke, England), and in brain heart infusion broth (Difco Laboratories) and in nutrient broth (Oxoid Limited). Strains of bacteria from other genera were grown on blood agar (as above) and cultivated as listed in table 1.

All strains of bacteria were grown in vitro as appropriate, and killed with $1 \%$ (v:v) formalin in phosphate buffered saline (PBS, Oxoid Limited).

\section{SPECIFICITIES OF THE ANTIBODIES}

The formalised suspensions of bacteria were diluted to about $5 \times 10^{7}$ bacterial cell $/ \mathrm{ml}$, and $0.02 \%$ (v:v) normal formolised yolk sac (prepared in DMRQC) added. Using this bacterial suspension, about 200 bacteria per high power field were observed using the method described below.

The bacterial suspension was spotted ( $5 \mu$ l volumes) on to $3 \mathrm{~mm}$ diameter wells on microscope slides coated with PTFE (Hendley, Essex), air dried, and fixed by total immersion in acetone for 10 minutes. Dilutions of whole ascitic fluid (between the end point and at 10 times stronger than this) from CL2 and CL17 were added to appropriate wells in $10 \mu$ l volumes, and these were incubated in a damp box for 30 minutes at $37^{\circ} \mathrm{C}$. The slides were washed in PBS for 10 minutes (with two changes) and air dried. Ten $\mu$ l of the anti-mouse FITC conjugate was added (diluted to optimum in PBS), and the slides were incubated and washed as before.

After drying the slides were examined by epiillumination using a Zeiss microscope equipped with $\times 10$ eyepieces, $\times 63$ water immersion objective, HB 050 mercury vapour lamp, and interference filters (excitation KP 490 and LP $455 \mathrm{~nm}, 510 \mathrm{~nm}$ dichroic mirror, and barrier filters BP 520-560 nm and BP 590 $\mathrm{nm})$.

EXAMINATION OF NECROPSY TISSUE

Impression smears were prepared on glass microscope slides from necropsy tissue, air dried, and fixed in 
Table 1 Species and strains of bacteria, and culture methods used to assess specificities of two anti-Listeria monoclonal antibodies

Number of strains/species/method of cultivation/strain designation

14 Staphylococcus aureus' (NCTC 8530, NCTC 8531, NCTC 8532, NCTC 6131, NCTC 6133, NCTC 6134, NCTC 6135, NCTC 6136, NCTC 6137, NCTC 8722, NCTC 8723 , NCTC 8724 , NCTC 8725 , NCTC 8726 )

7 Erysipelothrix rhusiopathiae' (NCTC 8163, NCTC 807, NCTC 11002, NCTC 11003, NCTC 11004, NCTC 11005 , NCTC 11006)

1 Corynebacterium ulcerans' (NCTC 7910)

1 Corynebacterium pyogenes ${ }^{2}$ (NCTC 5224)

1 Corynebacterium haemolyticum ${ }^{2}$ (NCTC 9697)

1 Corynebacterium pseudotuberculosis' (NCTC 3450)

1 Corynebacterium pseudodiphtheriticum' (NCTC 1136)

1 Corynebacterium aquaticum' (NCTC A53/80)

1 Bifidobacterium bifidum ${ }^{3}$ (NCTC 10471)

1 Cellulomonas biazotea ${ }^{2}$ (NCTC 10823)

1 Cellulomonas fimi ${ }^{2}$ (NCTC 7547)

1 Brevibacterium sp $^{2}$ (NCTC 11083)

1 Brevibacterium ammoniagenes' (NCTC A26/74)

1 Arthrobacter globiformis ${ }^{1}$ (NCTC A56/80)

1 Kurthia zopfii ${ }^{3}$ (NCTC 10597)

1 Lactobacillus casei ${ }^{3}$ (NCTC 10302)

2 Lactobacillus odontolyticus $^{3}$ (NCTC 1406, NCTC 1407)

1 Brochothrix thermosphacta ${ }^{2}$ (NCTC 10822)

1 Clostridium absonum ${ }^{3}$ (NCTC 10984)

1 Clostridium aerofoloetidum ${ }^{3}$ (NCTC 505)

1 Clostridium bifermentans ${ }^{3}$ (NCTC 506)

1 Clostridium butyricum ${ }^{3}$ (NCTC 7423)

1 Clostridium carnis $^{3}$ (NCTC 10913)

1 Clostridium celatum ${ }^{3}$ (NCTC 10947)

1 Clostridium chauvoei ${ }^{3}$ (NCTC 8070)

1 Clostridium difficile ${ }^{3}$ (NCTC 11209)

1 Clostridium fallax ${ }^{3}$ (NCTC 8380)

1 Clostridium histolyticum ${ }^{3}$ (NCTC 503)

1 Clostridium scatologenes ${ }^{3}$ (NCTC 9800)

1 Clostridium septicum ${ }^{3}$ (NCTC 547)

1 Clostridium tertium ${ }^{3}$ (NCTC 541)

1 Clostridium tetanomorphum ${ }^{3}$ (NCTC 2909)

1 Clostridium novyi ${ }^{3}$ (NCTC 538)

2 Bacillus megaterium' (FH 918/82, FH 923/82)

2 Bacillus licheniformis' (FH 931/82, FH 957/82)

2 Bacillus sphaericus' (FH 901/82, FH 1364/82)

1 Bacillus marcerans' (FH 902/82)

1 Bacillus polymyxa' (FH 1335/82)

2 Bacillus subtilis' (FH 956/82, FH 961/82)

2 Bacillus pumilus' (FH 970/82, FH 1023/82)

2 Bacillus cereus' (FH 903/82, FH 1081/82)

1 Bacillus circulans' (FH 921/82)

5 Streptococcus Lancefield group B' (NCTC 8181, NCTC 11248 , NCTC 11078 , NCTC 11079 , NCTC 11080)

9 Streptococcus Lancefield group D' (NCTC 8727, NCTC 8729, NCTC 8730, NCTC 8731, NCTC 8732, NCTC 8734, NCTC 8735, NCTC 8744, NCTC 7171)

5 Escherichia coli type $\mathrm{Kl}^{\prime}$ (NCTC 9001, NCTC 9002, NCTC 9006, NCTC 9007, NCTC 11101) acetone for 10 minutes. Direct FITC conjugates of CL2 and CL17 were diluted to their optimal working strength in PBS, and $200 \mu$ l added to an area of the slide containing the fixed tissue (about $2 \mathrm{~cm}^{2}$ ). The slides were incubated for 30 minutes at $37^{\circ} \mathrm{C}$, washed in PBS twice over 10 minutes, and examined by epifluorescence microscopy as before.

\section{SPECIMENS AND CASE HISTORIES OF THE PATIENTS}

Formalin fixed necropsy tissue was obtained from four patients:

Case 1

A 22 year old woman, 12 weeks pregnant, was admitted to hospital after complaining of headache, photophobia, loose stools and dry cough during the preceding 14 days, and of fever and rigors for two days. On examination no central nervous system abnormalities were detected, except for minimal neck stiffness. A thick brownish discharge was seen in the cervical canal. A provisional diagnosis of viral meningitis with threatened abortion was made. ${ }^{24}$

While in hospital, a fresh fetus was aborted which had a crown-rump length of $5.6 \mathrm{~cm}$, and had septic lesions over the thoracic wall. Multiple abscesses were seen on the surface of the placenta.

$L$ monocytogenes serovar $1 / 2 \mathrm{~b}$ was isolated from maternal blood cultures, amniotic fluid, chorioallantoic membrane, and from the thoracic wall of the fetus. In addition, Gram positive bacilli were seen in impression smears taken from the placenta and the liver and kidney of the fetus.

Case 2

A 60 year old man who had received aortic and mitral valve replacements 15 years previously died after a four day illness with fever. Post mortem examination showed "ring abscesses" in the tissue surrounding the mitral and aortic prosthetic valves. $L$ monocytogenes serovar $4 \mathrm{~b}$ was isolated from blood cultures and from tissue in the region of the aortic and mitral valve rings.

Case 3

A previously healthy 85 year old man was admitted to hospital with a clinical diagnosis of "encephalitis" complicated by pneumonia. Despite aggressive antimicrobial treatment with cefotaxime and Acy-

$1=$ Grown aerobically at $37^{\circ} \mathrm{C}, 2=$ Grown aerobically at $30^{\circ} \mathrm{C}$.

$3=$ Grown anaerobically at $37^{\circ} \mathrm{C}$.

NCTC $=$ National Collection of Type Cultures, Colindale, FH = Food Hygiene Laboratory, Colindale.

Sources and strain designations are shown in parentheses after the name of the bacterium. All strains were grown on blood agar, and harvested after 18 hours' incubation. 
clovir he died 72 hours after admission. Gram positive rods were seen in a necrotic area of the brainstem, and $L$ monocytogenes serovar $1 / 2$ a was cultured from the brain-stem tissue and meningeal swabs.

\section{Case 4}

A previously healthy 50 year old woman was admitted to hospital with a 10 day history of headache and dizziness of gradual onset, accompanied by nausea and vomiting, and later dysarthria and transient diplopia. On examination, she was toxic and feverish $\left(38.5^{\circ} \mathrm{C}\right)$ and had nystagmus and incoordination of movement, but no papilloedema.

A computed tomography scan showed a relatively low density area in the mid-brain, but cerebrospinal fluid showed normal cell and glucose content and no bacteria were isolated on culture. A further sample of CSF examined 48 hours later showed 24 lymphocytes/ $\mathrm{mm},{ }^{3}$ but was otherwise normal. Blood cultures were not obtained.

A diagnosis of herpes simplex encephalitis was considered a strong possibility and she was treated with Acyclovir and dexamethasone. Despite an initial improvement she developed a complete upper brain stem palsy and a further computed tomography scan showed an extension of the abnormality in the upper brain stem to the cerebellum, the appearance suggesting an infarct. She died five days later of respiratory failure.

As the brain was fixed at necropsy culture was not possible. Following fixation the mid-brain and upper pons were found to be totally destroyed by a subacute inflammatory process with necrotic areas in which numerous Gram positive coccobacilli were present. Abscesses were also present in the thalamus and the cerebellum but there was no evidence of meningitis.

\section{Results}

\section{SPECIFICITY OF THE ANTIBODIES}

The reaction of the antibodies with strains of Listeria and other species of bacteria is shown in table 2 .

The strains of Listeria were initially tested when grown on Difco Tryptose Agar. The monoclonal antibody CL17 reacted with 61 of the $64(95 \%) L$ monocytogenes serogroup $1 / 2$ and serogroup 3 strains tested, but did not react with strains of $L$ monocytogenes serogroups 4 or 7 , or with strains from the remaining species of Listeria (with the exception of the type strain of $L$ seeligeri, which is serovar $1 / 2 b$ ). The antibody CL2 reacted with all 77 of the $L$ monocytogenes serovar $4 \mathrm{~b}$ strains, just over half $(13 / 24)$ of other $L$ monocytogenes serogroup 4 strains, and with all five of the $L$ innocua serovar 6 a strains tested. This antibody did not react with the $L$ monocytogenes serogroup $1 / 2$ or serogroup 3 strains, or any of the other remaining species of Listeria. Strains of $L$
Table 2 Results of specificity testing of two anti-Listeria monoclonal antibodies against 187 strains of Listeria, and 87 strains of bacteria from 14 other genera

\begin{tabular}{llr}
\hline & $\begin{array}{l}\text { No of strains of bacteria } \\
\text { which reacted with the } \\
\text { antibody/total number of } \\
\text { strains }\end{array}$ \\
\cline { 2 - 3 } & $\begin{array}{l}\text { Anti-Listeria monoclonal } \\
\text { antibody }\end{array}$ \\
\cline { 2 - 3 } & CL2 & CL17 \\
Strains of bacteria & $0 / 14$ & $50 / 52$ \\
\hline L monocytogenes serogroup 1/2 & $0 / 12$ & $11 / 12$ \\
L monocytogenes serogroup 3 & $77 / 77$ & $0 / 12$ \\
L monocytogenes serovar 4b & $13 / 24$ & $0 / 6$ \\
L monocytogenes serogroup 4 not 4b & $0 / 1$ & $0 / 1$ \\
L monocytogenes serovar 7 & $5 / 5$ & $0 / 5$ \\
L innocua serovar 6a & $0 / 5$ & $0 / 5$ \\
L innocua serovar 6b & $0 / 1$ & $0 / 1$ \\
L welshimeri & $0 / 1$ & $1 / 1$ \\
L seeligeri & $0 / 6$ & $0 / 6$ \\
Livanovii & $0 / 1$ & $0 / 1$ \\
L murrayi & $0 / 1$ & $0 / 1$ \\
L grayi & $0 / 1$ & $0 / 1$ \\
L denitrificans & $0 / 87$ & $0 / 87$ \\
Other species of bacteria & &
\end{tabular}

monocytogenes serogroup $1 / 2,3$ and 4 were further tested when grown using blood agar, brain heart infusion broth, and nutrient broth. No differences in the specificities of the antibodies were detected using the growth obtained from these four different media.

No strong cross reactions with other species of bacteria were observed. Some of the strains of Staphylococcus aureus (known to contain Fc receptors on the cell surface), however, did react non-specifically with the dilutions of ascitic fluid and also with the FITC conjugated anti-mouse antibody. These reactions were not observed when the bacteria were pretreated with normal rabbit sera or when the FITC conjugated anti-Listeria monoclonal antibodies were used. This suggests that these reactions were of a nonimmune nature.

\section{REACTIVITY OF THE MONOCLONAL ANTIBODIES WITH NECROPSY SPECIMENS}

Results of immunofluorescence microscopy are shown in table 3. Bacteria were observed in material from cases 1,2 , and 3 , which had reacted with the monoclonal antibody of the specificity corresponding to that of the serogroup of the isolate of $L$ monocytogenes from each of the patients. Extremely large numbers of bacteria were seen in the impression smears taken from cases 1 and 2.

Bacilli reacting with CL2 (and hence presumably $L$ monocytogenes serogroup 4) were seen in the material from case 4. 
Table 3 Results of direct immunofluorescence tests using FITC conjugates of anti-Listeria monoclonal antibodies tested against necropsy tissue

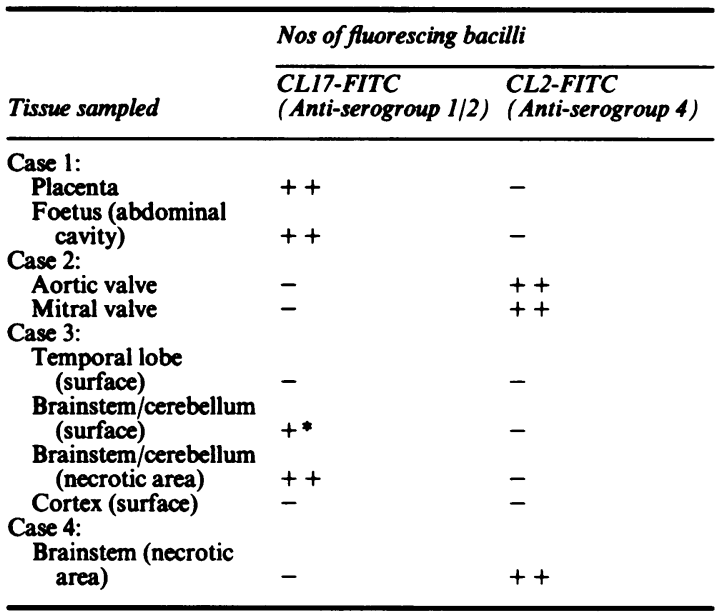

*Scanty numbers of bacilli only seen.

\section{Discussion}

Antigenic cross reactions between $L$ monocytogenes and species of Staphylococcus, Erysipelothrix, Bacillus, Streptococcus, Corynebacterium, Lactobacillus and Escherichia coli have been reported. ${ }^{1725-36}$ The monoclonal antibodies described here were shown to be specific for certain serovars of Listeria, but the possibility of cross reactions can not entirely be excluded as only a limited number of heterologous strains have been tested here, and these were cultured using a single set of growth conditions. It should be borne in mind that the cell surface (and presumably its antigenic nature) of bacteria may change depending on the culture conditions. ${ }^{37}$ The antigens detected on the cell surface of $L$ monocytogenes by the monoclonal antibodies, however, were present when the bacteria were grown under a number of different conditions. In addition, the observation presented here showing that these antigens are expressed in vivo confirms that these are relatively stable characteristics.

Several workers have reported the use of FITC conjugated antibodies ${ }^{38-40}$ and bacteriophages ${ }^{41}$ for the identification of $L$ monocytogenes in clinical and environmental material. The monoclonal antibodies described here have the advantages over conventionally produced antisera of better reagent reproducibility and ease of production.

When tested against strains of $L$ monocytogenes, the monoclonal antibodies were broadly serogroup specific, but neither reacted in a manner identical with that of the factor sera described in the Donker-Voet/ Seeliger antigenic scheme. ${ }^{18}$ This suggests that the antigens reacting with the monoclonals are related to, but may not necessarily be identical with, those recognised in this scheme.

The incidence with which each serogroup of $L$ monocytogenes causes infection in man in Britain has been reported. ${ }^{5}$ Using this information, together with the results in table 2 , it can be estimated that when present in clinical specimens, strains of $L$ monocytogenes in over $95 \%$ of all patients with listeriosis will be detected using these two monoclonal antibodies. This estimate assumes that the specificities of these antibodies are similar with respect to bacteria grown in vitro and in vivo. Our results indicate this to be the case, although only a very limited number of necropsy specimens have so far been examined.

Several authors ${ }^{242} 43$ have reported the presence of Gram positive coccobacilli and bacilli in the body fluids (especially CSF) of patients with listeriosis, which were either not cultured, or if so, only with difficulty. Problems in culturing bacteria after patients have started to receive antimicrobial chemotherapy are well recognised. Infections of the central nervous system by $L$ monocytogenes are not always meningitic, ${ }^{44}$ examination of the CSF may not show any abnormalities, ${ }^{4647}$ and even if $L$ monocytogenes is grown from the CSF it may be misidentified ${ }^{48}$ and dismissed as a contaminant. Early diagnosis and treatment of perinatal listeriosis may modify the poor prognosis of this infection, ${ }^{9950}$ and it has been suggested that the examination of placental, cord and amniotic cells for Gram positive bacilli may aid diagnosis. ${ }^{501}$ In addition, listeriosis may be diagnosed only following necropsy. ${ }^{52}$

We acknowledge the assistance of Dr D Samuel and Mr A Grant of DMRQC, Central Public Health Laboratory, Colindale, for help in this study. We also thank Dr I Wilson at Ashford Hospital, and Mr JB Miles at Walton Hospital for the permission to report on two of the cases described in this paper.

\section{References}

1 Murray EGD, Webb RA, Swann MBR. A disease of rabbits characterised by a large mononuclear leucocytosis, caused by a hitherto undescribed bacillus bacterium monocytogenes (n.sp.). J Pathol Bacteriol 1926;29:407-39.

2 Gray ML, Killinger AH. Listeria monocytogenes and listeric infections. Bact Rev 1966;30:309-82.

3 Seeliger HPR, Finger H. Listeriosis. In: Remington JS, Klein JO, eds. Infectious diseases of the fetus and newborn infant. 2nd ed. Philadelphia: WB Saunders, 1983:264-89.

4 Anonymous. Communicable disease quarterly. Public Health Laboratory Service, Microbiology Digest 1986;3:35-7.

5 McLauchlin J. Listeria monocytogenes, recent advances in the taxonomy and epidemiology of listeriosis in humans. $J$ Appl Bacteriol 1987;63:1-11.

6 Anonymous. Listeria infections in farm animals. Editorial. Vet $\operatorname{Rec} 1983 ; 112: 314$.

7 Gitter M. A changing pattern of ovine listeriosis in Gt. Britain. In: Courtieu AL, Espaze EP, Reynaud AE, eds. Proceedings of the 
9th International Symposium on Problems of Listeriosis. Nantes: Universite de Nantes, 1986:294-9.

8 Schlech WF, Lavigne PM, Bortolussi RA, et al. Epidemic listeriosis: evidence for transmission by food. $N$ Engl J Med 1983;308:203-6.

9 Fleming DW, Cochi SL, MacDonald KL, et al. Pasteurized milk as a vehicle of infection in an outbreak of listeriosis. $N$ Engl J Med 1985;312:404-7.

10 James SM, Fannin SL, Agee BA, et al. Listeriosis outbreak associated with Mexican-style cheese-California. Morbidity and Mortality Weekly Report 1985;34:357-9.

11 Skerman VBD, McGowan V, Sneath PHA. Approved lists of bacterial names. Int J Syst Bacteriol 1980;30:225-420.

12 Moore WEC, Cato EP, Moore LVH. Index of the bacterial and yeast nomenclatural changes published in the International Journal of Systematic Bacteriology since the 1980 approved lists of bacterial names (1 January 1980 to 1 January 1985). Int J Syst Bacteriol 1985;35:382-407.

13 Ralovich B. Listeriosis research: present situation and perspective. Budapest: Akademiai Kiado, 1984.

14 Rocourt J, Seeliger HPR. Distribution des espèces du genre Listeria. Zentralbl Bakteriol Mikrobiol Hyg (A) 1985;259: 317-30.

15 Busch LA. Human listeriosis in the United States, 1967-1969. J Infect Dis 1971;123:328-32.

16 Rocourt J, Hof H, Schrettenbrunner A, Malinverni R, Bille J. Meningite purulente aigue à Listeria seeligeri chez un adulte immunocompetent. Schweiz Med Wochenschr 1986;116: 248-51.

17 Seeliger HPR. Listeriosis. 2nd ed. Basel: Karger, 1961.

18 Seeliger HPR, Hohne K. Serotyping of Listeria monocytogenes. In: Bergan T, Norris JR, eds. Methods in Microbiology. Vol. 13. New York: Academic Press, 1979:31-49.

19 McLauchlin J, Beesley JE, Betts MP. Monoclonal antibodies against Listeria monocytogenes serogroup 4 surface antigens. In: Courtieu AL, Espaze EP, Reynaud AE, eds. In Proceedings of the 9th International Symposium on Problems of Listeriosis. Nantes: Université de Nantes, 1986:102-5.

20 Russell WC, Patel G, Precious B, Sharp I, Gardner PS. Monoclonal antibodies against adenovirus type 5: Preparation and preliminary characterization. J Gen Virol 1981;56:393-408.

21 Samuel D, Patt RJ, Abuknesha RA. A sensitive method of detecting proteins on dot and western blots using a monoclonal antibody to FITC. J Immunol Methods 1988;107:217-24.

22 Rocourt J, Schrettenbrunner A, Seeliger HPR. Differenciation biochimique des groupes genomiques de Listeria monocytogenes (sensu lato). Ann Microbiol (Paris) 1983;134A: 65-71.

23 McLauchlin J, Audurier A, Taylor AG. The evaluation of a phagetyping system for Listeria monocytogenes for use in epidemiological studies. J Med Microbiol 1986;22:357-65.

24 Pezeshkian R, Fernando N, Carne CA, Simanowitz MD. Listeriosis in mother and fetus during the first trimester of pregnancy: case report. Br J Obstet Gynaecol 1984;91:85-6.

25 Drew RM. Occurrence of two immunological groups within the genus Listeria: studies based upon precipitation reactions. Proc Soc Exp Biol Med 1946;61:30-3.

26 Seeliger HPR, Sulzbacher F. Antigenic relationship between Listeria monocytogenes and Staphylococcus aureus. Can J Microbiol 1956;2:220-31.

27 Neter E, Anzai H, Gorzynski EA. Identification of an antigen common to Listeria monocytogenes and other bacteria. Proc Soc Exp Biol Med 1960;105:131-4.

28 Welshimer HJ. Staphylococcal antibody production in response to injections with Listeria monocytogenes. $J$ Bacteriol 1960;79:456-7.

29 Aalund O, Osebold JW, Murphy FA, Di Capua RA. Antibody heterogeneity in experimental listeriosis. $J$ Immunol 1966;97:150-7.

30 Larsen SA, Jones WL. Evaluation and standardization of an agglutination test for human listeriosis. Appl Microbiol
1972;24:101-7.

31 Minden P, McClatchy JK, Farr RS. Shared antigens between heterologous bacterial species. Infect Immun 1972;6:574-82.

32 Pease PE, Nicholls L, Stuart MR. Evidence that precipitin crossreactions between Listeria Erysipelothrix and Bacillus licheniformis are not due to the Rantz antigen. $J$ Gen Microbiol 1972;73:567-9.

33 Wilkinson BJ, Jones D. Some serological studies on Listeria and possibly related bacteria. In: Woodbine M, ed. Proceedings of the 6th International Symposium on Problems of Listeriosis. Leicester: Leicester University Press, 1975:251-61.

34 Antonissen ACJM, Van Kessel KPM, Van Dijk H, Willers JMN Development of a simple passive haemagglutination-inhibition assay for Listeria monocytogenes lipoteichoic acid. J Immunol Methods 1981;44:351-7.

35 Hether NW, Jackson LL. Lipoteichoic acid from Listeria monocytogenes. J Bacteriol 1983;156:809-17.

36 Hopfer RL, Pinzon R, Wenglar M, Rolston KVI. Enzyme release of antigen from Streptococcus faecalis and Listeria monocytogenes cross-reactive with Lancefield group G typing reagents. J Clin Microbiol 1985;22:677-9.

37 Ellwood DC, Tempest DW. Effects of environment on bacterial wall content and composition. In: Rose AH, Tempest DW, eds. Advances in microbial physiology. Vol 7. London: Academic Press, 1972:83-117.

38 Smith CW, Marshall JD, Eveland WC. Identification of Listeria monocytogenes by the fluorescent antibody technic. Proc Soc Exp Biol Med 1960;103:842-5.

39 Eveland WC. Demonstration of Listeria monocytogenes in a direct examination of spinal fluid by fluorescent-antibody technique. J Bacteriol 1963;85:1448-50.

40 Khan MA, Seaman A, Woodbine M. Immunofluorescent identification of Listeria monocytogenes. Zentralbl Bakteriol Mikrobiol Hyg (A) 1977;239:62-9.

41 Watson BB, Eveland WC. The application of the phagefluorescent antiphage staining system in the specific identification of Listeria monocytogenes. J Infect Dis 1965;115:363-9.

42 Hone R, Marshall P, Cran H. Listeria monocytogenes meningitis in a healthy adult. $J$ Irish Med Assoc 1972;65:81-2.

43 Green HT, Macaulay MB. Hospital outbreak of Listeria monocytogenes septicaemia: a problem of cross infection? Lancet 1978;ii:1039-40.

44 Nieman RE, Lorber B. Listeriosis in adults: a changing pattern: report of eight cases and review of the literature, 1968-1978. Rev Infect Dis 1980;2:207-27.

45 Pollock SS, Pollock TM, Harrison MJG. Infection of the central nervous system by Listeria monocytogenes: a review of 54 adult and juvenile cases. $Q J$ Med 1984;211:331-40.

46 Kennard C, Howard AJ, Scholtz C, Swash M. Infection of the brainstem by Listeria monocytogenes. J Neurol Neurosurg Psychiatr 1979;42:931-3.

47 Trautmann $M$, Wagner J, Chahin M, Weinke T. Listeria meningitis: report of ten recent cases and review of current therapeutic recommendations. J Infect 1985;10:107-14.

48 Dee RR, Lorber B. Brain abscess due to Listeria monocytogenes: case report and literature review. Rev Infect Dis 1986;8:968-77.

49 Robertson MH, Mussalli NG, Aizad TA, Okaro JM, Banwell GS. Two cases of perinatal listeriosis. Arch Dis Child 1979;54:549 62.

50 Relier JP. Perinatal and neonatal infections: Listeriosis. $J$ Antimicrob Chemother 1979;5A:51-7.

51 Khong TY, Frappell JM, Steel HM, Stewart CM, Burke M. Perinatal listeriosis: a report of six cases. Br J Obstet Gynaecol 1986;93:1083-7.

52 Klatt EC, Pavlova Z, Teberg AJ, Yonekura ML. Epidemic perinatal listeriosis at autopsy. Hum Pathol 1986;17:1278-81.

Requests for reprints to: Dr J McLauchlin, Division of Microbiological Reagents and Quality Control, 61 Colindale Avenue, London NW9 5HT, England. 